\title{
Research on The Application of Caliper Assembly Line Improvement Based on Work Study
}

\author{
Min Tang, Jijun Xiao*, Zheng Qin and Dongliu Tan \\ Business School of Guilin University of Electronic Technology Guilin, Guangxi, 541004, China \\ ${ }^{*}$ Corresponding author
}

\begin{abstract}
The heavy logistics, discrete operation floor, volume work in process, high-intensity operation and informal operational standards are taken as the production problems of digital caliper assembly in the $G$ company. According to the problems mentioned above, the improvement scheme of caliper assembly line has been proposed based on work study. By Using 5 W1H questioning technique, ECRS principle, stopwatch time study and Flexsim software simulation, the improving purposes combine bottleneck process improvement, the cycle time determination and assembly line layout adjustment. The results of alternative scheme shows that the equilibrium rate has increased to $81.62 \%$ compared with the original data $69.7 \%$, the production cycle has been slashed $46.3 \mathrm{~s}$, production output has been increased by 169 and operational procedures become more standardized. These improvements can provide reference and guidance for digital caliper assembly production in the G company. The combination of business case study makes perfect sense to laboratory simulation experiments.
\end{abstract}

Keywords-work study; lean production; assembly line balancing

\section{INTRODUCTION}

The work study in IE theory is the mature and favorable tool to improve productivity, eliminate waste and reduce the cost. The work study includes method study and work measurement. Method study use a variety of analytical techniques to recorded, inspect, analyze and improve current operation method, then put forward more economic, more reasonable, more effective work methods. With the application above, the consumption of personnel, machines and other resources can be reduced. In the course of standardization, work measurement uses a variety of techniques to measure qualified workers according to the operation standard formulation and calculate needed time to perform a specific job. Methods study focuses on the improvement of work methods, while the effect of its application relay on the work measurement. Work measurement is committed to reduce the invalid time in production and determine the standard time .In a word, work study is the combination of engineering activity, homework optimization technique and memory scientific method taking operating system as the research object. Under the condition of the production technology in certain organization, the application of work measurement and method study can improve the productivity of the system by analyzing unreasonable, wasteful and confused factors and seeking better work method. The production line balancing and process optimization are treated as main purpose. A type of digital caliper assembly line was analyzed and improved in this study based on work study and work measurement. The optimization was carried out further by the simulation programming.

\section{ThE StATUS AND DATA ANALYSIS}

\section{A. The Survey of Caliper Process}

The production of digital calipers in $G$ company is composed of diverse workshops: machine shop, dynamic gate production workshop, assembly workshop, clean workshop and packaging workshop. After the completion of the previous task, the job will be delivered to the next process. The caliper assembly workshop was selected to investigate, which requires the semi-finished products and parts transported by the previous workshop. Workers can't start assembling jobs until all the parts arrive to assembly workshop. The current assembly process can be divided into five steps.

Through field measurement and analysis for each process unit of product assembly, the data has been shown in TABLE 1 according to stopwatch time study and statistics on staff.

TABLE I. The Caliper Assembly Time of Each Process

\begin{tabular}{c|c|c|c}
\hline Process & Name & Personnel & Unit Time (s) \\
\hline 1 & assembly & 16 & 203.05 \\
\hline 2 & head and tail & 2 & 17.45 \\
\hline 3 & inverted burr & 2 & 13 \\
\hline 4 & burring claw & $6-7$ & 52 \\
\hline 5 & quality check & 6 & 61.6 \\
\hline
\end{tabular}

B. Analysis of Existing Problems

The problems in enterprises are presented so faintly that staff should possess question awareness and find the problems existing in the work. Secondly, it is necessary to check the past statistical data carefully(machine efficiency, operation rate, the rate of finished products, etc.). On the basis of understanding the caliper production assembly process and work arrangement in $\mathrm{G}$ company, the survey was carried out to confirm problems effectively. The detailed information and questionnaire is shown: (1) production $(\mathrm{P})$ : Whether the productivity has been declined? Can the production efficiency be improved? (2)Quality (Q): Whether the quality of the product has been decreased or the failure rate has been higher? Can the qualification rate be improved? (3)Cost(C): Whether the cost has been improved? Whether the consumption of raw materials and fuel has been increased? (4)The delivery date (D): Can the 
delivery time be met? Can the production time be shorten? (5)Security(S): Are there any safety problems? Are there many security risks? (6)Morale (M): Whether the allocation of operations personnel is reasonable? Whether the staff have morale and enthusiasm? Is there any problem in the relationship of operators? (7)Environment (E): Is the local working condition good? Can it meet the demands of employees? The existing problems have been found and shown: (1) Due to distributed work table, the linking of processes is discrete and can't reflect problems timely. (2) There are a lot of handling work, which results in time waste and make people fatigue.(3) The large backlog of products. Due to the adoption of the work and the disparity of operation method and operation time, the completed time of back and forth operations is different, which lead to waiting time and many WIP inventory. (4) Without the observation of standard operation, the operation methods and operation time among the fellow processes appears apparent differences.

\section{IMPROVEMENT METHOD OF PRODUCTION LiNE}

Through the analysis of digital caliper assembly process in $\mathrm{G}$ company and combination of the actual situation, the lean production line design simulation experiment relying on the industrial engineering laboratory was carried out. The Flexsim software was used to simulate assembly process under the flow shop condition. In order to eliminate waste and standardize design, the assembly line balancing emerges specific production index. The laboratory has designed a lean production line to students, which can enhance students manipulative ability and professional knowledge effectively. The simulation data exerting from laboratory will provide guidance for actual production.

\section{A. The Scope of Study}

According to TABLE 1, the assembly process is the most time-consuming process, which accounts for $56 \%$ of the total production time. The company's production scale has reached an annual output of 1.6 million units; the improvement of process will improve the production efficiency of the assembly process significantly. At the same time, considering the assembling caliper equipment and some related technologies can not be achieved in the laboratory. The design of production line affect the level of production capacity directly, one or several bottleneck stations often affect the whole production capacity. It is the key issues to improve the production capacity and solve the bottleneck station in the design of the pipeline. Therefore, we the scope of is designed as follows:

- The design scope: the assembly process of the digital caliper.

- The confirmation of design goal: To carry out process analysis and design when measuring all the processes by stopwatch time study.

\section{B. The Analysis of Assembly Process}

Based on $\mathrm{G}$ company's original calipers, the application of 5W1H questions technology has been shown in TABLE 2.
TABLE II. 5W1H QUESTIONS TABLE

\begin{tabular}{l|l|l}
\hline No. & \multicolumn{1}{|c}{ Problem } & \multicolumn{1}{c}{ Analysis } \\
\hline 1 & $\begin{array}{l}\text { Can we cancel the process of } \\
\text { checking frame? Why? }\end{array}$ & No, it is used to test quality. \\
\hline 2 & $\begin{array}{l}\text { Can we cancel the process of } \\
\text { filing head and tail? Why? }\end{array}$ & $\begin{array}{l}\text { No, Removing chip ensures the } \\
\text { surface smooth. }\end{array}$ \\
\hline 3 & $\begin{array}{l}\text { Can we foot combine the } \\
\text { inspection and the filing job? }\end{array}$ & Yes. \\
\hline 4 & $\begin{array}{l}\text { Can we cancel assembly process } \\
\text { of moving gate? Why? }\end{array}$ & $\begin{array}{l}\text { No, the gate is the display module } \\
\text { in caliper. }\end{array}$ \\
\hline 5 & $\begin{array}{l}\text { Are there any better ways to } \\
\text { screwing? }\end{array}$ & $\begin{array}{l}\text { Yes, double hands work analysis } \\
\text { can shorten the time to screwing. }\end{array}$ \\
\hline 7 & $\begin{array}{l}\text { Can we cancel the process of } \\
\text { separate frame? }\end{array}$ & $\begin{array}{l}\text { No, the job of pasting fixed gate } \\
\text { and scale can't be conducted } \\
\text { without separating frame. }\end{array}$ \\
\hline 8 & $\begin{array}{l}\text { Can we cancel pressing? why? } \\
\text { process of frame? Why? }\end{array}$ & $\begin{array}{l}\text { Yes, it can be replaced by double- } \\
\text { sided tape. }\end{array}$ \\
\hline 9 & $\begin{array}{l}\text { Can we advance the inspection } \\
\text { job? Why? }\end{array}$ & $\begin{array}{l}\text { No, It is used to ensure product } \\
\text { correction. }\end{array}$ \\
\hline
\end{tabular}

\section{The Improvement of Assembly Line Balancing}

The balancing of flow line requires a reasonable division of assembly operations, so that the comprehensive working time is no longer than rhythm of production capacity. Before organizing production line, the rhythm of the production line is the first term to be considered on account of defined output every day (or other time units).The design of production line requires caliper assembly to yield no less than 600 a day (the production per capita is about 130). The daily effective working time is 8 hours, $C t=48 s$ is the rhythm value. According to the current bottleneck process, the production jobs can't be finished on time unless we improve operating time for each process.

It is the first step to delete unnecessary and informal operation and focus on the bottleneck process, such as assembling movable gate and sticking fixed gate. In order to make working time consensus and maintain line balancing as far as possible, the Flexsim simulation in the laboratory is applied to combine and simplify operations. Based on the separation and combination of assembling movable gate and sticking fixed gate, the improved standard laboratory working time is created by stopwatch time study. The specific work contents of A, B, C and D ( filing head and tail and mounting movable gate, installing the battery and pasting fixed gate, sticking scale and assembling fixed gate and correcting indication and using platen ). Combining the calculated value, the number of working stations of flow line can be determined. The calculation is as follows.

$$
S_{\text {min }}=\left[\frac{W}{C T}\right]=\frac{\sum_{\mathrm{i}=1}^{\mathrm{s}} \frac{t_{i}}{C T}}{C T}=\left[\frac{156.71}{48}\right] \approx 4
$$

In order to determine the observation time and design the pipeline, the formulation of pipeline equilibrium rate is as follows. 


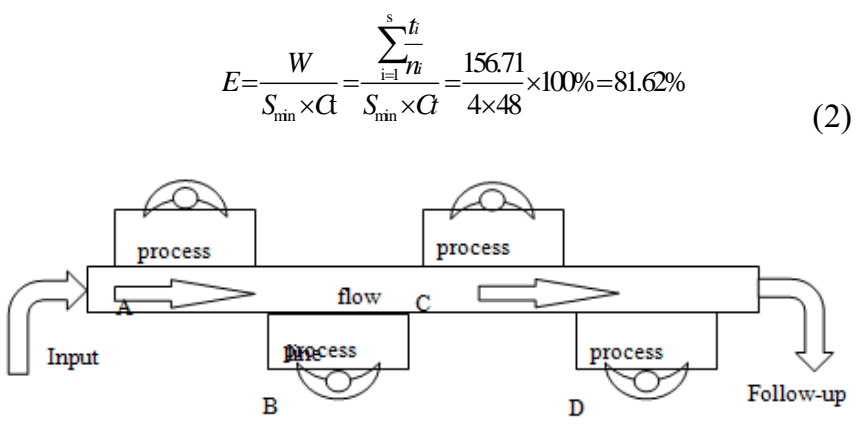

FIGURE I.

PRODUCTION LINE LAYOUT IN LABORATORY

\section{Production Line Simulation}

The general procedure of system simulation can be described as system investigation, system model establishment, simulation algorithm determination, simulation model establishment, simulation model operation, simulation results analysis, simulation result output, system programs analysis, system parameters modification and simulation analysis recycle. The recycle of procedure won't finish until the end of simulation.

Based on the collected data, the Flexsim simulation arrangement of production line table was designed in accordance with FIGURE I. After installing processing logic of each work table, the model is operated to generate the Flexsim State Report in TABLE 3 and TABLE 4 automatically. The word 'idle' in the table means idle time, 'processing time' is equal to the working time, and 'output' represents the quantity of output. In order to express the condition of working station per day (8h). $8 * 60 * 60=28800$ s was regarded as daily working time in this simulation.

Comparing the original data with laboratory data in Table 3 and 4 , the output and equilibrium rate in laboratory simulation have been enhanced. Stats output raised from 453 to 622 and the totality has increased by 169 . The average processing of four process (filing head and tail and mounting movable gate, installing the battery and pasting fixed gate, sticking scale and assembling fixed gate and correcting indication and using platen) raised from $80.5 \%$ to $84.8 \%$, each process has increased by $4.3 \%$ equally.

TABLE III. FLEXSIM STATE REPORT (ORIGINAL DATA)

\begin{tabular}{c|c|c|c|c}
\hline Time: & \multicolumn{4}{|c}{$28800 \mathrm{~s}$} \\
\hline Object & Class & Idle & Processing & Stats output \\
\hline Inflow of raw materials & Source & $0.00 \%$ & $0.00 \%$ & 457 \\
\hline $\begin{array}{c}\text { Filing head and tail and } \\
\text { mounting movable gate }\end{array}$ & Processor & $22.30 \%$ & $72.70 \%$ & 456 \\
\hline $\begin{array}{c}\text { Installing the battery and } \\
\text { pasting fixed gate }\end{array}$ & Processor & $43.58 \%$ & $56.32 \%$ & 455 \\
\hline $\begin{array}{c}\text { Sticking scale and assembling } \\
\text { fixed gate }\end{array}$ & Processor & $0.38 \%$ & $93.52 \%$ & 454 \\
\hline $\begin{array}{c}\text { Correcting indication and } \\
\text { using platen }\end{array}$ & Processor & $0.53 \%$ & $99.47 \%$ & 453 \\
\hline Subsequent processing & Sink & $0.00 \%$ & $0.00 \%$ & 0 \\
\hline
\end{tabular}

TABLE IV. FLEXSIM STATE REPORT (LABORATORY DATA)

\begin{tabular}{c|c|c|c|c}
\hline Time: & \multicolumn{4}{c}{ 28800s } \\
\hline Object & Class & Idle & Processing & Stats output \\
\hline Inflow of raw materials & Source & $0.00 \%$ & $0.00 \%$ & 625 \\
\hline $\begin{array}{c}\text { Filing head and tail and } \\
\text { mounting movable gate }\end{array}$ & Processor & $0.19 \%$ & $99.81 \%$ & 624 \\
\hline $\begin{array}{c}\text { Installing the battery and } \\
\text { pasting fixed gate }\end{array}$ & Processor & $24.91 \%$ & $75.09 \%$ & 623 \\
\hline $\begin{array}{c}\text { Sticking scale and assembling } \\
\text { fixed gate }\end{array}$ & Processor & $6.72 \%$ & $93.28 \%$ & 622 \\
\hline $\begin{array}{c}\text { Correcting indication and } \\
\text { using platen }\end{array}$ & Processor & $28.97 \%$ & $71.03 \%$ & 622 \\
\hline Subsequent processing & Sink & $0.00 \%$ & $0.00 \%$ & 0 \\
\hline
\end{tabular}

\section{Evaluation}

After the redesign and recombining of digital caliper assembly processes in the laboratory, the flow line production campaign was conducted with the equilibrium rate of $81.62 \%$. On account of the repeated practice in laboratory, the comparison of improvement effect is presented in TABLE 5.

TABLE V. TABLE OF EFFECT COMPARISON

\begin{tabular}{l|l}
\hline \multicolumn{1}{c|}{ Before Improvement } & \multicolumn{1}{c}{ After Improvement } \\
\hline $\begin{array}{l}\text { (1) There was heavy work in process } \\
\text { and unnecessary wait and the original } \\
\text { balance was 69.70\%. }\end{array}$ & $\begin{array}{l}\text { (1) Work in process has been } \\
\text { reduced to zero and the balance } \\
\text { rate has improved to 81.62\%. } \\
\text { (2)Without specific assurance measures } \\
\text { for standard, employees owned low } \\
\text { awareness and movement on the sense } \\
\text { was too frequent. }\end{array}$ \\
$\begin{array}{l}\text { (3)Due to the inconsistent working time } \\
\text { and training system, the field } \\
\text { of each process, much waiting time } \\
\text { wasn't necessary. }\end{array}$ & $\begin{array}{l}\text { (3)It has been apparent that the } \\
\text { production cycle slashed by 46.34s } \\
\text { and production increased by 169. } \\
\text { (4)The survey has provided an } \\
\text { opportunity practice for students } \\
\text { and made students grasp more } \\
\text { professional knowledge. }\end{array}$ \\
\hline
\end{tabular}

In the laboratory, the proportion of the entire production process has reduced apparently and the total assembly time has reduced by 23 percent approximately. With the optimization of work in process, waiting waste and other issues, the simulation can provide effective guidance to assembly enterprises.

\section{RECOMMENDATIONS AND CONCLUSIONS}

The recommendations have been provided through analysis in the laboratory and comparison with G company's original method.

1) Due to the heavy work in process, the current production mode causes waiting waste and fund occupation. The corresponding workers had better to deliver jobs to following process timely.

2) The method study should get more attention and standard operation methods affects the productivity greatly. The standard awareness of employees can be strengthened through regular training or hold a corresponding activity, which can reduce the defect rate effectively. 
3) The leadership should act as the role mode. When receiving the improvements or nice suggestions proposed by staff, they ought to render corresponding praise and motivation.

Lean production is one of the advanced manufacturing technologies in the contemporary era; its wide application to China's manufacturing industry has brought a profound impact. At present, Industrial engineering technology is not widely used in Chinese small and medium enterprises. In order to maintain normal production, the existing caliper assembly process was improved by work study in this article. According to the original data in company, the lean assembly line has been designed by test and simulation in laboratory. The production has increased by 169 and the balance has increased by $11.92 \%$ when compared with the existing assembly process. The conclusion with strong practicality can provide practical guidance for the company's production. Meanwhile, this type of survey not only enhances students' applications in professional knowledge, but also promotes the interaction among students, business and universities.

\section{ACKNOWLEDGMENTS}

This research is supported by National Training Programs of Innovation and Entrepreneurship for Undergraduates (201410595020).

\section{REFERENCES}

[1] HUANG Yin-di, BIAN Rong-hua, ZHANG Jun.Study on Logistics Simulation Software Application at Home and Abroad[J]. Industrial Engineering and Management2010(03),124-128.

[2] LIAO Ji-lin, LIU Jian-yi. Research on Enterprise Organization Reconstruction Based on BPR[J]. Study on Technology Economy and management2010(2),98-101.

[3] LI Zhao-jun, LIU Yang, LONG Hui. Nonlinear Vibration Reliability of Hydraulic Turbine-generator Units with Multiple Failure Modes[J]. Journal of Mechanical Engineering,2013,16:170-176.

[4] G.Lanza, Capability Assessment and Valuation of the Implementation of Lean Production Methods in Turbulent Environments, A.Jondral.J.Book, 15 September 2011, 524-529.

[5] Kathrin Peter and Gisela Lanza .Company-specific quantitative evaluation of lean production methods, Production Engineering, February 2011, Volume 5, Issue 1, pp 81-87.

[6] Radu F. Babiceanu and Remzi Seker .Manufacturing Operations, Internet of Things, and Big Data: Towards Predictive Manufacturing Systems, Volume 594 of the series Studies in Computational Intelligence pp 157-164, 18 February 2015.

[7] Giovanni Miragliotta, Fadi Shrouf. Using Internet of Things to Improve Eco-efficiency in Manufacturing: A Review on Available Knowledge and a Framework for IoT Adoption, Volume 397 of the series IFIP Advances in Information and Communication Technology pp 96-102.

[8] D. Mourtzis.Challenges and future perspectives for the life cycle of manufacturing networks in the mass customisation era, Logistics Research. 05 January 2016.

[9] Yi Shu-ping.Work study and Human Factors Engineering[M].Beijing, Tsinghua University press,2011(11).

[10] WU Chao-ran, LI Fang.To Improve and Optimize Business Process Based on Methods Study and Witness Simulation[J].Industrial Engineering and Management,2014,05:43-51

[11] Xue Wei, Jiang Zu-hua. Introduction of Industrial Engineering [M]. Beijing: Mechanical Industry Press, 2009.5,44-48.

[12] Kan Shu-lin. Basic Industrial Engineering [M]. Beijing: Higher Education Press, 2005 151-161.
[13] GUO Fu, ZHANG Guo-min, WEN Jie.Application of Work Study to the Throughput Balance of Car Assembly Line[J].Industrial Engineering and Management,2006,02:119-122+126.

[14] LIN Yu, QI Er-shi. The Study of China Industry Engineering's Developing Status and Application in Manufacturing Enterprises[J].Science and Management of Science and Technology,2007,04:148-152.

[15] Wang Hong-wei, Xie Yong, Wang Xiao-ping. Logistics System Simulation[M].Beijing, Tsinghua University press,2008. 